\title{
Synthesis of a Retinoic Acid Receptor Agonist
}
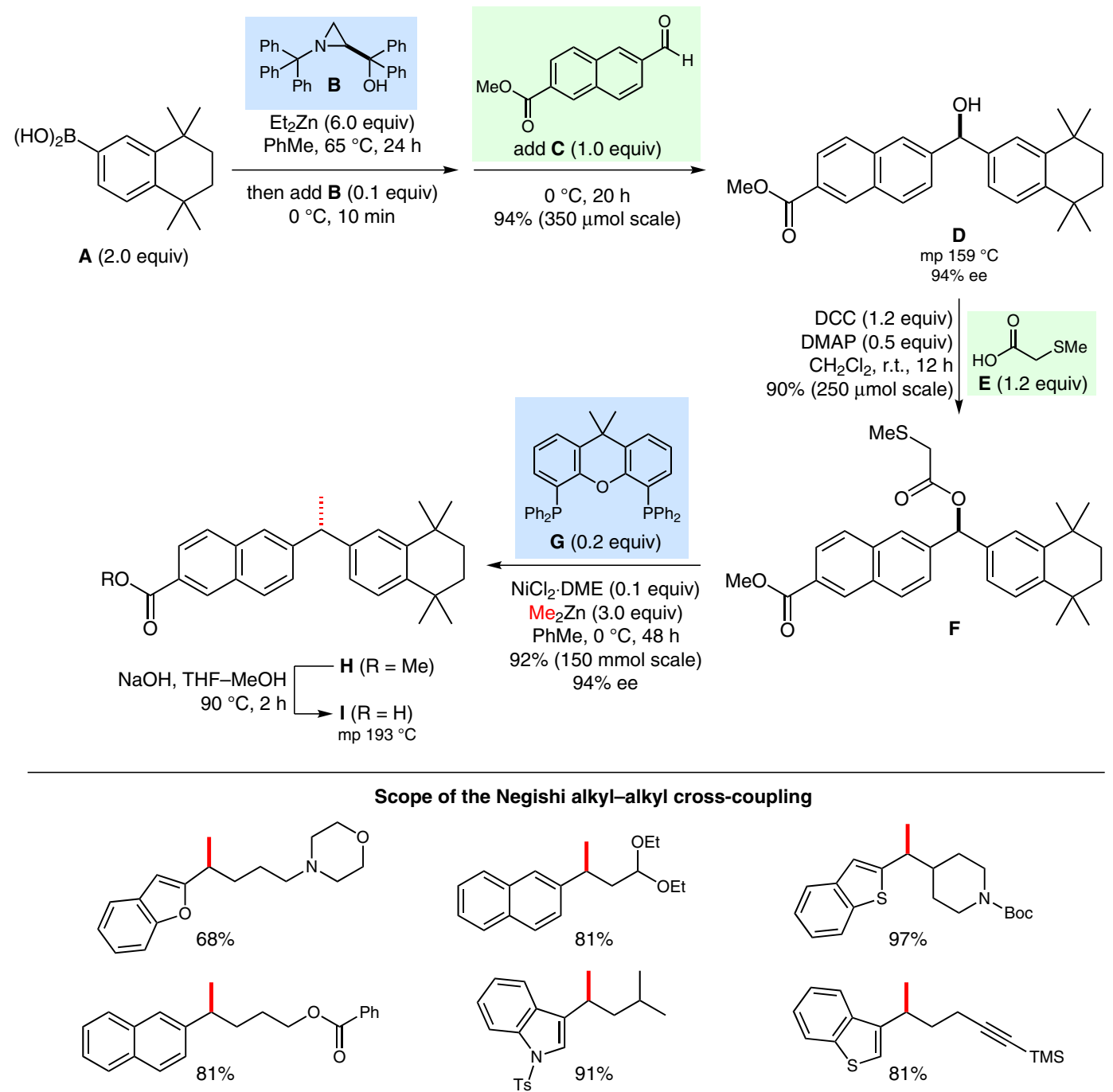

Significance: The target molecule $\mathbf{I}$ is a retinoic acid receptor $\gamma(\mathrm{RAR} \gamma)$ agonist that is of interest for the treatment of acne, psoriasis and melanoma. The synthesis depicted features the first nickel-catalyzed stereospecific Negishi alkyl-alkyl cross-coupling reaction of secondary benzylic $\alpha$-(methylthio)acetate esters with dimethylzinc. SYNFACTS Contributors: Philip Kocienski

Synfacts 2013, 9(9), 0917 Published online: 19.08.2013

Dol: 10.1055/s-0033-1339523; Reg-No.: K04713SF

\section{Gategory}

Synthesis of Natural

Products and

Potential Drugs

\section{Key words}

retinoic acid receptor agonist

nickel-catalyzed cross-coupling

$\alpha$-(methylthio)acetate esters

dimethylzinc

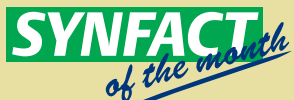

Comment: The mild reaction conditions are compatible with a variety of functional groups including alkenes, protected alkynes, acetals, and esters. Heterocycles, amines, and imides are also well tolerated. Cross-coupling with diethylzinc is also possible but the reaction is more complex owing to additional competitive reaction pathways. 